\title{
Highlights of the Symposium on Gold/Silver Catalysis, EuropaCatV, Limerick, Ireland, 3-5 September 2001
}

\author{
David T Thompson \\ Consultant to World Gold Council \\ 'Newlands', The Village, Whitchurch Hill, Reading, RG8 7PN \\ E-mail:DTThompson@aol.com
}

This was the second major international conference on gold catalysis to be held this year (2001): a clear indication of the new interest being developed by the recent advances in the subject. These were easily the biggest gatherings ever held on this topic and attendance at the second was significantly bigger than at the first. This meeting consisted of four half-day sessions, taking place on Monday afternoon, Tuesday (all day) and Wednesday morning, and a poster session on the Tuesday evening. All five sessions were well attended, with between about 70 and over 200 participants being present at all the sessions. The quality of both oral and poster presentations was high and lively discussion was stimulated by almost all of them. There were 25 orals and 17 posters and of these, 19 of the orals and 13 of the posters were principally or entirely on gold catalysis. Most of the participants were from academia but there was also a significant number of industrial personnel present and it became clear during the discussions that a number of industrial organizations are assessing the catalytic properties of gold, and this is supported by increased patent activity (1).

The first, Cape Town Conference on Catalytic Gold has been reported previously (1), and the purpose of this report is to highlight the new information presented at this Limerick Symposium. Both symposia included papers on homogeneous and liquid and gas phase heterogeneous gold catalysis research. Limerick also had a paper on electrocatalysis by gold and silver (A.J. Ahern, L.D. Burke, L.M. Hurley and A.P. O'Mullane, University College of Cork, Ireland), a topic which also promises to have unique and useful features with potential applications.

\section{KEYNOTE LECTURES}

The excitement which has been generated by the new results in gold catalysis was immediately evident from the large attendance at the talk, given by Professor Graham Hutchings (Cardiff University), entitled 'The Current Status of Catalysis by Gold'. He pointed out that there has been a renaissance of interest in the use of gold as a catalyst in reactions relevant to both chemical processing and pollution control. Reactions include carbon monoxide oxidation, water gas shift, hydrochlorination and selective hydrogenation (1). This talk was illustrated by examples where supported gold has been demonstrated to be the best catalyst. The importance of gold particle size and other physical and preparative variables was indicated. Professor Robert Schlögl of the Fritz-Haber-Institut, Berlin followed this with a talk on 'The Current Status of Catalysis by Silver'. Elemental silver is a unique catalyst for selective oxidation reactions, amongst which ethylene epoxidation and methanol oxidation are used commercially.

\section{HOMOGENEOUS CATALYSIS}

The first presentation was by Professor Stephen Hashmi of the University of Stuttgart. He started by saying that one of the few chemical elements that everyone knows about and that has fascinated mankind for a long time, $i e$ gold, is usually associated with high value and low reactivity. But nowadays gold is significantly cheaper than other precious metals (eg Rh, Pt and Pd) used in technical applications; this is true for both the price per gram as well as the price per mole. Gold is also refined in much larger quantities than the Platinum Group Metals. In catalysis reactions an increasing number of publications document the potential for soluble gold catalysts for highly efficient and selective transformations (2).

Professor Hashmi then talked about homogeneous gold-catalysed organic reactions involving $\mathrm{C}-\mathrm{C}$ bond 
formation, such as the cycloisomerization/dimerization of allenyl ketones and Michael acceptors, and the synthesis of highly substituted arenes from easily accessible furyl alkynyl compounds. All the reactions proceed at room temperature and under neutral conditions, no precautions such as the exclusion of water or oxygen are necessary. Due to the absence of paramagnetic species, the reactions can conveniently be monitored using NMR specroscopy. In both types of conversions the $\mathrm{C}-\mathrm{C}$ bond formation is accompanied by an additional C-heteroatom bond formation, and the interesting mechanistic aspects of these goldcatalysed reactions were discussed.

Another homogeneous catalysis paper was given by Dr Qiang Xu of the National Institute of Industrial Science and Technology, Osaka, Japan. The title was 'A New Gold Catalyst: Formation of Gold(I) Carbonyl, $[\mathrm{Au}(\mathrm{CO}) n]^{+}(n=1,2)$, in Sulfuric Acid and its Application to Carbonylation of Olefins'. The $[\mathrm{Au}(\mathrm{CO}) n]^{+}(n=1,2)$, was readily synthesized from commercial gold(III) oxide, $\mathrm{Au}_{2} \mathrm{O}_{3}$, in concentrated sulfuric acid, which exhibits high catalytic activity for

$$
\begin{gathered}
\stackrel{\mathrm{Au}_{2} \mathrm{O}_{3}}{\stackrel{\mathrm{H}_{2} \mathrm{SO}_{4}}{\longrightarrow}} \mathrm{Au}^{3+}(\text { solv }) \stackrel{\mathrm{CO}}{\longrightarrow} \mathrm{Au}^{+}(\text {solv }) \\
\underset{\mathbf{C O}}{\longrightarrow}[\mathrm{CO})]^{+} \underset{-\mathrm{CO}}{\stackrel{+\mathrm{CO}}{\rightleftarrows}} \underset{\mathbf{2}}{\stackrel{\left.\mathrm{Au}(\mathrm{CO})_{2}\right]^{+}}{\longrightarrow}}
\end{gathered}
$$

carbonylation of olefins:

The gold monocarbonyl $[\mathrm{Au}(\mathrm{CO})]^{+}(\mathbf{1})$ and dicarbonyl $\left[\mathrm{Au}(\mathrm{CO})_{2}\right]^{+}(\mathbf{2})$ cations co-exist in sulfuric acid, and 1<smiles>[R]C=C[CH+][R]C(C)CC</smiles><smiles>[R]C(C)(C(=O)O)C([R])(C)C(=O)O</smiles>

is much more stable than 2, but 2 is an active catalyst:

The gold(I) carbonyl solution is an excellent catalyst for the reaction between olefins and $\mathrm{CO}$ to give tert-carboxylic acids in good yields at room temperature and atmospheric pressure. The gold(I) dicarbonyl cation $\mathbf{2}$ was found to function as an active species for the carbonylation. An olefin-gold(I)carbonyl complex was proposed as a possible intermediate.

\section{HETEROGENEOUS CATALYSIS IN THE LIQUID PHASE}

Amongst the papers presented in this section, that on electrocatalysis by gold was perhaps the most original as far as most of the participants were concerned. Andrea Ahern, speaking on behalf of Professor Declan Burke's research group at the University College, Cork, Ireland, gave a talk entitled 'The Quantum Dot Model of Active Site Behaviour at Gold and Silver Electrodes in Aqueous Media' and indicated that the catalytic action of metal surfaces is often a highly localized phenomenon, confined to $c a 2 \%$ of the surface metal atoms. Some surface atoms, probably those present at active sites, have a low lattice coordination number (LCN) and a low lattice stabilization energy, and are therefore highly active from both a thermodynamic and kinetic viewpoint. Recent results have suggested that gold in aqueous media exhibits two types of electrochemistry, based on the existence of two limiting surface metal atom states, one (the conventional state) in which the LCN value is high and a second (the superactive state) in which the LCN value is low.

Gold is not a strong chemisorber, but superactive surface gold atoms have properties which are quite different from similar atoms at conventional gold surfaces: they are much more electropositive and have many more of their co-ordination sites exposed to solution species. It was concluded that quite often catalysis at gold surfaces involves species, eg metal atoms and their oxidation products, reacting under conditions which are thermodynamically quite unfavourable to the existence of such states.

In a poster by $S$ Galvagno et al of the Università di Messina, Italy, the liquid phase oxidation of salicylic alcohol using gold catalysts was described. The reaction is carried out under very mild conditions $\left(50^{\circ} \mathrm{C} / 1\right.$ atm) using gold supported on $\mathrm{Fe}_{2} \mathrm{O}_{3}$. The activation energy of the reaction in the range $30-80^{\circ} \mathrm{C}$ is 15 $\mathrm{Kcal} / \mathrm{mol}$, regardless of the gold loading and the method used for preparation of the catalysts (wetness impregnation or coprecipitation).

Liquid phase oxidative catalysis by gold was also described by Serena Biella, one of Professor Rossi's research group at the University of Milan, Italy. Immobilisation of gold sols was used to prepare highly active gold on carbon catalysts, useful in the selective liquid phase oxidation of diols (1). Aminoalcohols can also be selectively oxidized to aminoacid in slightly alkaline solution: this is an application in which gold excels for the amino group strongly interacts with other catalytic metals. 


\section{GAS PHASE HETEROGENEOUS CATALYSIS}

Most of the gold catalysis work to date falls into this category. Results reported are relevant to pollution control, chemical processing or fuel cell applications, dependant on the reaction involved. More mechanistic studies have been done on the carbon monoxide oxidation reaction than any other.

\section{Oxidation of Carbon Monoxide}

By far the greatest number of papers was presented on this topic. The research objectives vary from increased understanding of the reaction mechanism to a desire to apply the technology, as outlined in the talk by Professor $B E$ Nieuwenhuys of Leiden Institute of Chemistry, The Netherlands. The research project at Leiden is motivated by:

a) The search for improved automotive catalysts and alternative fuels in connection with the more stringent legislation required for automotive exhaust gas catalysis.

b) The search for catalysts selective in $\mathrm{CO}$ oxidation in the presence of hydrogen. These catalysts are required for the generation of electrical energy by using the polymer electrolyte fuel cell (PEFC).

In this context the following reactions are being studied:

1) The oxidation of $\mathrm{CH}_{4}$

2) The oxidation of $\mathrm{H}_{2}$ at low temperatures

3) The oxidation of $\mathrm{CO}$ at low temperatures and the effect of $\mathrm{H}_{2} \mathrm{O}$ on the activity

4) The selective oxidation of $\mathrm{CO}$ by $\mathrm{O}_{2}$ in the presence of $\mathrm{H}_{2}$

The catalysts used in these studies have included gold on $\gamma-\mathrm{Al}_{2} \mathrm{O}_{3}$ and several $\mathrm{Au}-\mathrm{MO}_{\mathrm{x}}$ on $\gamma-\mathrm{Al}_{2} \mathrm{O}_{3}$ catalysts, with $\mathrm{MO}_{\mathrm{x}}$ being a metal oxide $(\mathrm{M}=\mathrm{Mg}, \mathrm{Cr}, \mathrm{Mn}, \mathrm{Fe}$, $\mathrm{Co}, \mathrm{Ni}, \mathrm{Cu}$, and $\mathrm{Zn}$ ). The effects of the gold particle size and the presence of $\mathrm{MO}_{\mathrm{x}}$ on the activity and the selectivity was investigated.

It has generally been accepted that the presence of small gold particles is beneficial to obtain high activity $(3,4)$. For $\mathrm{CH}_{4}$ oxidation on $\mathrm{Au} / \gamma-\mathrm{Al}_{2} \mathrm{O}_{3}$ also a clear particle size effect was observed. Both the activity in $\mathrm{CO}$ and, to a lesser extent, $\mathrm{CH}_{4}$ oxidation on $\mathrm{Au} / \gamma$ $\mathrm{Al}_{2} \mathrm{O}_{3}$ can be improved upon addition of $\mathrm{MO}_{\mathrm{x}}$. The effect of $\mathrm{MO}_{\mathrm{x}}$ on the oxidation activity may be twofold. On the one hand, $\mathrm{MO}_{\mathrm{x}}$ can stabilize small gold particles and may participate in the reaction by supplying active oxygen. The catalysts used in these studies showed an increased activity towards CO oxidation upon addition of water, only when small

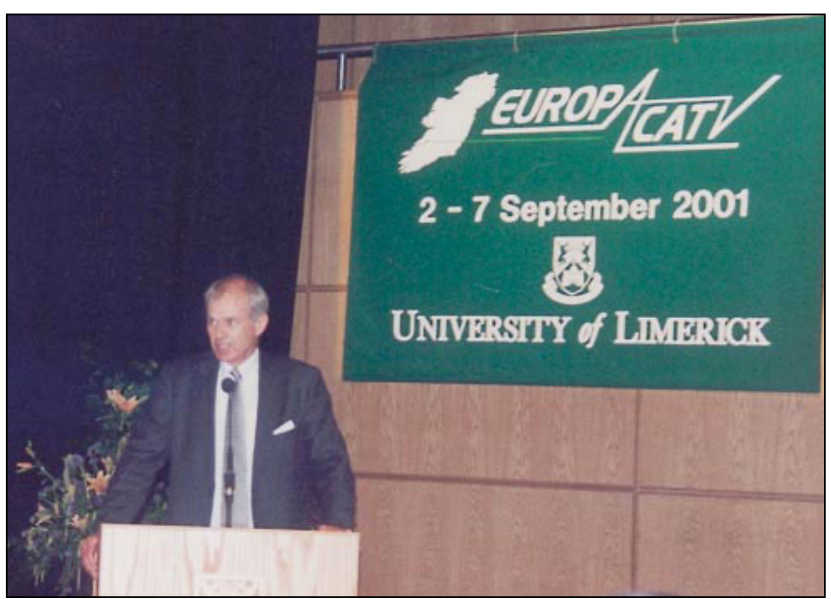

Figure 1 Professor Julian Ross introducing the EuropaCatV Conference

gold particles $(<5 \mathrm{~nm})$ were present.

Generally, the activity of gold-based catalysts in hydrogen oxidation is lower than in CO oxidation. This rather special ability, typical of supported gold catalysts, was employed in order to put together a highly active and selective catalyst for $\mathrm{CO}$ oxidation in the presence of hydrogen.

The CO oxidation reaction is catalysed by supported gold catalysts at temperatures as low as 90 $\mathrm{K}$. In an FTIR study of $\mathrm{CO}$ adsorption and oxidation on gold-titania catalysts at this temperature, Professor Flora Boccuzzi of the Università di Torino, Italy has found that if the gold particle size was less than $5 \mathrm{~nm}$, then $\mathrm{CO}$ and oxygen are competitively adsorbed on gold step sites, but if the gold particle size is $>10.6 \mathrm{~nm}$ in size then the reaction does not occur at all at $90 \mathrm{~K}$.

One of the talks which attracted most attention was that given by Professor Mayfair Kung of the Department of Chemical Engineering, Northwestern University, Evanston, USA. Following the report by Haruta et al (5) that gold supported on transition metal oxides is very active for $\mathrm{CO}$ oxidation, it had been observed that $\mathrm{Au} / \gamma-\mathrm{Al}_{2} \mathrm{O}_{3}$ is active for the selective catalytic oxidation (SCO) of CO in hydrogen. These two reactions differ in that while the $\mathrm{CO}$ conversion activity is stable in SCO, it declines rapidly with time on stream in $\mathrm{CO}$ oxidation. Thus, the presence of hydrogen during SCO successfully prevented deactivation. It was also found that $\mathrm{Au} / \gamma-\mathrm{Al}_{2} \mathrm{O}_{3}$ catalyst deactivated in the course of $\mathrm{CO}$ oxidation could be effectively regenerated by exposure to hydrogen at room temperature. The extent of regeneration, however, depended on the partial pressure of hydrogen, the duration of hydrogen treatment and the history of the sample. The activity 


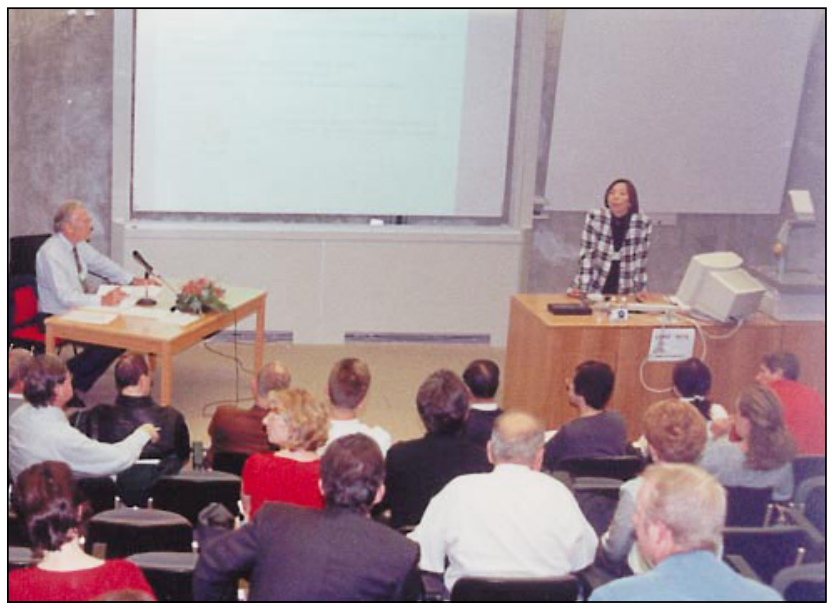

Figure 2 Professor Mayfair Kung delivering her talk during the Au/Ag Symposium

could be fully restored by flowing the SCO feed over the catalyst. Regeneration could also be achieved by flowing $\mathrm{He}$ containing $1.8 \%$ water vapour. Conversely, significant loss in $\mathrm{CO}$ conversion was observed when $\mathrm{Au} / \gamma-\mathrm{Al}_{2} \mathrm{O}_{3}$ catalyst was heated to $100^{\circ} \mathrm{C}$ or higher in dry $\mathrm{He}, \mathrm{O}_{2}$ or $\mathrm{H}_{2}$. Again, such a thermally deactivated catalyst can be fully regenerated by a short exposure to the SCO feed.

These results suggest that the active sites contain hydroxyl groups, which could be removed by dehydroxylation or by $\mathrm{CO}$ oxidation. The mild temperature needed for the dehydroxylation suggests that the hydroxyl groups are associated with Au. These hydroxyl groups participate in the reaction possibly by reaction with $\mathrm{CO}$ to form an active intermediate in the $\mathrm{CO}_{2}$ production pathway. Deactivation during $\mathrm{CO}$ oxidation is due to the depletion of the hydroxylated active sites when the reaction intermediate transforms into a stable surface species. These surface species, possibly surface carbonate, can be removed by reaction with hydrogen to regenerate the hydroxyl groups. The effectiveness of the SCO feed in regeneration is because hydrogen can be oxidized to water and react with the stable surface species that poison the active site. Consistent with the interpretation that an hydroxylated species is part of the active site is the high susceptibility of these catalysts to poisoning by chloride ions, since the chloride may displace the $\mathrm{OH}$ groups.

Dr Masakazu Date, a member of Dr Haruta's group at the Osaka National Research Institute, Japan talked about the mechanism for $\mathrm{CO}$ oxidation over gold catalysts. A correlation exists between small particle sizes and high activity. The contact between the gold particles and the titania support plays a crucial role. The reaction order is almost zero with respect to the partial pressure of $\mathrm{CO}$ and oxygen. There are at least three reaction phases with different apparent activation energies: below $250 \mathrm{~K}$ the reaction takes place over the gold surface, whereas above $300 \mathrm{~K} \mathrm{CO}$ adsorbed on the gold surface reacts with oxygen diffusing from the support surface. At intermediate temperatures the reaction rate is probably limited by the accumulation of carbonate species at the perimeter interface between the gold particle and the titania support.

Professor Lidun An of the Institute of Applied Catalysis, Yantai, PR China, proposed a mechanism for carbon monoxide oxidation based on the structure characterization of $\mathrm{Au} / \mathrm{Fe}_{2} \mathrm{O}_{3}$ catalysts. The possible catalytically active state is the partially oxidized gold $\left(\mathrm{Au}^{\delta+}\right)$ with unoccupied outer $d$ orbitals, similar to the outer $d$ orbital structure of Pt. Thus 'inert' gold can become very active for $\mathrm{CO}$ oxidation.

Anke Wolf of the Max Planck Institut für Kohlenforschung, Mulheim an der Ruhr, Germany reported that for a series of gold on metal oxide supports, the highest catalytic activity for $\mathrm{CO}$ oxidation was obtained using $\mathrm{Au} / \mathrm{TiO}_{2}$ or $\mathrm{Au} / \mathrm{Co}_{3} \mathrm{O}_{4}$ prepared by deposition precipitation. For these precipitated materials the catalytic activity increased with increase of $\mathrm{pH}$ during the precipitation; the optimum $\mathrm{pH}$ being between 8 and 9. The catalytic activity was also found to increase with decreasing calcination temperature, the most active catalysts having been calcined at $200^{\circ} \mathrm{C}$. Both of these effects were attributed to decreasing gold particle size.

'The Investigation of Gold Catalysts Prepared via a Gold Colloid Route' was the title of the talk given by Jan-Dierk Grunwaldt of the Swiss Federal Institute of Technology, ETH-Zentrum, Switzerland. The gold catalysts prepared by this route had particle sizes of 2 -

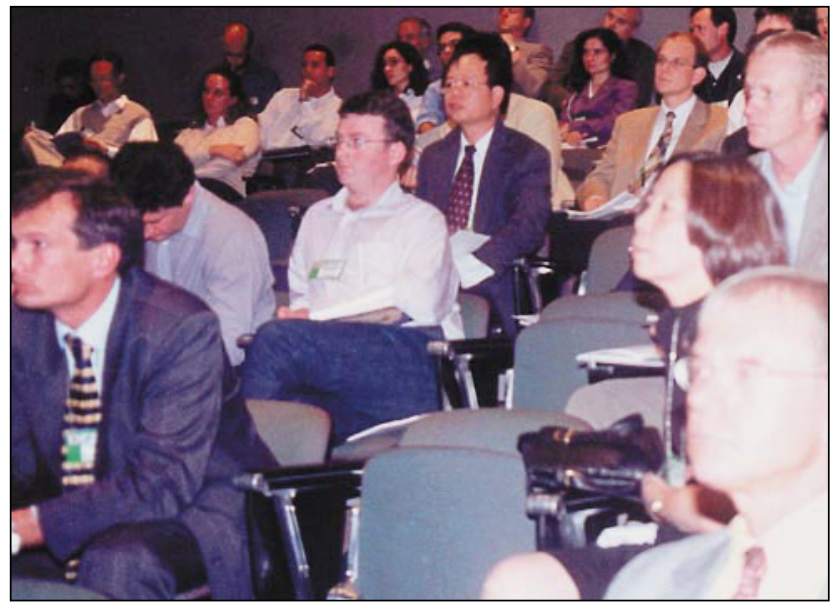

Figure 3 Part of the audience at an Au/Ag Symposium presentation 


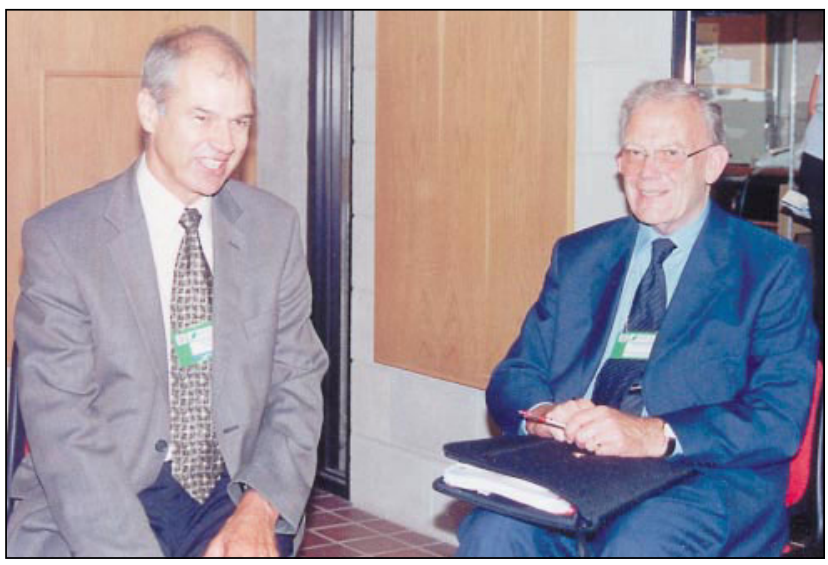

Figure 4 Conferring during a coffee break!

$2.5 \mathrm{~nm}$ on both titania and zirconia and the activity of the titania-supported catalysts was much higher. The maximum activity was obtained for titania catalysts calcined at $500^{\circ} \mathrm{C}$. XPS, TEM and XRD measurements are consistent with the gold being mostly in the metallic state. A mechanism involving reaction of $\mathrm{CO}$ with molecular oxygen was suggested.

Professor Norbert Kruse of the Université Libre de Bruxelles, Belgium described the results of his group's Field Ion Microscopy (FIM) work. High-resolution FIM-images of clean tips were obtained with hydrogen and neon as imaging gas. Between 300 and $450 \mathrm{~K}$ the exposure of a clean gold sample to $\mathrm{O}_{2}$ gas at 100-1000 mbar, in the absence of an electric field, led to oxygen chemisorption and formation of a "surface oxide". The presence of an electric field of 12-15 V/nm was found to enhance the oxidation process. Exposure to $\mathrm{CO}$ gas at $300 \mathrm{~K}$ led to the removal of the surface oxide. This was associated with the occurrence of a wave front which started in the apex centre and extended to the outskirts of the tip sample. The build-up of the surface oxide and its titration by carbon monoxide was completely reversible. The results strongly suggest that pure gold crystals are active catalysts for carbon monoxide oxidation at $300 \mathrm{~K}$.

The application of pressure was reported to enable the measurement of $\mathrm{CO}$ chemisorption in a paper delivered by Professor Jozsef Margitfalvi of the Hungarian Academy of Sciences, Budapest, using gold supported on $\mathrm{MgO}$ and $\mathrm{Mg}(\mathrm{OH})_{2}$. Under these conditions the $\mathrm{CO}$ was predominantly adsorbed on the gold rather than the support. TPR and time on stream (TOS) experiments indicate that the activity of the $\mathrm{Au} / \mathrm{MgO}$ catalysts strongly depend on the mode of their preparation. The activity of $\mathrm{Au} / \mathrm{MgO}$ catalysts is controlled by the mode of reduction of the gold precursor compound in the slurry, (b) the temperature of oxygen and hydrogen treatment prior to the reaction: hydrogen reduction improves activity

Pulsed flow reactor studies of $\mathrm{CO}$ on Au catalysts were described by Jorge Soares from Professor Michael Bowker's group at Reading University, UK. From results to date it has been concluded that the active site might well involve an oxygen vacancy at the periphery of the gold nanoparticles, and these are lowered in concentration in the presence of excess oxygen.

Dr Gary Pattrick from Mintek, Randburg, South Africa described the Project Autek research on goldcatalysed oxidation of $\mathrm{CO}$ on $\mathrm{Fe}_{2} \mathrm{O}_{3}, \mathrm{Co}_{3} \mathrm{O}_{4}$ and mixtures of these two oxides. This is the group lead by Drs Mike Cortie and Elma van der Lingen, whose work was summarized in the Cape Town conference report (1).

\section{Catalytic Combustion of Volatile Organic Compounds}

Simona Minico described the work taking place in Professor Signorino Galvagno's group at the Univerity of Catania, Italy. The light-off temperatures for VOCs was lower than those observed for the reference support oxide samples, prepared using the same method as for the gold catalysts. The order of reactivity for the organic substrates was 2-propanol > acetone > toluene. The selectivity to $\mathrm{CO}_{2}$ for the 2-propanol oxidation was highest on the samples prepared using deposition precipitation and a low calcination temperature than those prepared by coprecipitation: this is thought to be due to the presence of small gold particles which activate lattice oxygen.

\section{Selective Oxidation of Propene}

Dr Guido Muldescribed the results obtained by the group working at the Delft University of Technology (1), and the same group presented a poster on propene oxidation over silver catalysts. Gold catalysts can very selectively produce propene oxide (PO) from propene, oxygen and hydrogen, but these catalysts give low PO yields (up to $2 \%)$ and a low efficiency in hydrogen. The low PO yield has been explained by its slow desorption. The mechanism proposed involves formation of hydrogen peroxide-like species over gold. The deactivation of the $\mathrm{TiO}_{2}$ catalysts is thought to be caused by irreversible adsorption of a propoxy species on selective Ti sites.

\section{Catalyst Preparation and Characterization}

The methods used to prepare gold catalysts, including deposition precipitation, coprecipitation, vapour deposition and impregnation featured in most papers, 
but Rodolfo Zanella from Catherine Louis' group at the Université Pierre et Marie Curie, Paris, focused his paper on this aspect. This group looked at suitable methods for increasing metal loading or decreasing the particle size. The use of urea rather than sodium hydroxide during deposition precipitation produces a small gold particle size $(2.9 \mathrm{~nm})$ and a higher metal loading $(8.3 \mathrm{wt} \% \quad \mathrm{Au})$. Cation exchange with $\left[\mathrm{Au}(\mathrm{en})_{2}\right]^{3+}$ on titania gives a catalyst with low gold loading $(2.4 \mathrm{wt} \%)$ and small gold particle size $(2.1 \mathrm{~nm})$.

Professor Takayoshi Uematsu of Chiba University, Japan described the preparation of two types of fine particles using the solution spray reaction (SPR) and the suspended spray reaction (SSR) techniques which had been developed to improve higher dispersion of metal clusters on the outer surface of the supports. After hydrogen treatment, the gold crystallite sizes were much smaller by SSR and the catalysts prepared by this method had much higher activities for $\mathrm{CO}$ oxidation. High temperature calcination promotes stronger interaction between the $\mathrm{Au}$ and the $\mathrm{TiO}_{2}$ giving rise to a dramatic decrease in activation energy and a corresponding increase in turnover frequency (TOF).

Dr Norbert Ernst of the Fritz-Haber Institute, Berlin described the photon emission spectroscopy work on individual oxide-supported silver and gold clusters in the scanning tunneling microscope, as described by Professor H-J Freund in Cape Town (1).

There was a poster presentation by G Martra et al from the Università di Torino, Italy on highly dispersed $\mathrm{Au} / \mathrm{SiO}_{2}$ catalyst obtained by deposition of gold sols derived from $\mathrm{NaBH}_{4}$ reduction of $\mathrm{Au}\left(\mathrm{PPh}_{3}\right) \mathrm{Cl}$. The activity of the catalyst for $\mathrm{CO}$ oxidation was studied in the as prepared, calcined (ie activated in oxygen at 673 $\mathrm{K})$ and reduced (ie activated in hydrogen at $673 \mathrm{~K}$ ) forms.

Another strongly preparation-orientated piece of research was described in the poster presented by Salvatore Scirè of the Università di Catania. In addition to TEM, the new low-frequency Raman modes (LFR) technique was used to measure the gold particle size in Au/iron oxide catalysts prepared by coprecipitation, deposition precipitation or impregnation.

\section{Theory}

There were two EuropaCatV presentations for which Professor Jens Norskov of the University of Denmark at Lyngby was co-author. The first, entitled 'Theoretical Study of the $\mathrm{Au} / \mathrm{TiO}_{2}(110)$ system', was given as a poster in the $\mathrm{Au} / \mathrm{Ag}$ Symposium. The studies relate to finding an explanation for why gold particles on reducible oxide supports can carry out oxygen transfer reactions with high efficiencies at ambient temperatures, thus leading to a loss of nobility by gold. The second was presented by Professor R-J Behm in the Surface Science and Model Catalysts Symposium. Bimetallic PdAu(111) surfaces were studied both experimentally and theoretically. Comparison with results of density functional calculations for $\mathrm{CO}$ and hydrogen adsorption on model surfaces with different ensembles yields excellent agreement with experimental data, both for adsorption energies and adsorption sites, for a number of different ensembles and allows a quantitative understanding of the underlying physical effects. This gives encouragement to further studies on bimetallic catalyst which frequently have superior performance to monometallic equivalents.

\section{CONCLUSIONS}

The interest in gold catalysis amongst academics is increasing, although there were comparatively few people who had attended both the Cape Town and the Limerick meetings: consequently the present author summarized the Cape Town talks for the benefit of the new participants, and suggested an overall interpretation of their potential for applications. The tangible evidence for increased interest in catalysis by gold was the high attendance at our symposium, and many of these participants probably had no direct involvement in gold catalysis before this meeting. There is a general feeling that the science being developed is still at a very early stage, but it is exciting and innovative and full of surprises. There is no doubt that the normal nobility of massive gold is changed by spreading small particles of the metal onto transition metal oxides, to give very reactive species, but there is still the confusion often present in the early days of a new scientific breakthrough regarding the best experimental conditions to prepare these catalysts. Reported results differ on precisely the best preparative route, the best calcination temperature and the best conditions under which to use the catalysts, but there is general agreement that gold can be a very active catalyst both under homogeneous and heterogeneous conditions. There is also ample scope for extending the range of catalysts used to include bimetallics and more supports (1).

In depth studies continue on the mechanism of $\mathrm{CO}$ oxidation and some on the mechanism for the selective oxidation of propene. However, as highlighted by Stephen Hashmi in the first issue of CatGold News (6), catalysis by gold has much wider potential and many more reactions should be investigated. Widening 
the research objectives could lead to innovative new chemical syntheses relevant to the kinds of high added value speciality products required by the pharmaceutical and related industries and more new technology relevant to pollution control and fuel cells.

Characterization of gold catalysts is unusually difficult. Normal chemisorption methods cannot be employed, but Jozsef Margitfalvi has reported chemisorption measurements under high pressures of $\mathrm{CO}$ for $\mathrm{Au} / \mathrm{MgO}$ and $\mathrm{Au} / \mathrm{Mg}(\mathrm{OH})_{2}$ catalysts. TEM and Mössbauer techniques must be used for particle size and oxidation state determinations. Small gold particles may sometimes be missed using TEM.

The ideas implied by the 'periphery' mechanism for $\mathrm{CO}$ oxidation suggested previously (7) received support from a consensus of speakers, ie a CO ligand attached to $\mathrm{Au}(0)$ is attacked by an hydroxyl group either on a support cation or a peripheral $\mathrm{Au}$ (III) ion, forming an hydroxyl group attached to the $\mathrm{Au}(\mathrm{III})$. This in turn is attacked by a superoxide ion, which is responsible for oxidizing two carboxylate groups. The hydroxyl group returns whence it came and is ready to re-engage in the catalytic cycle: The steps in the mechanism could include:

$$
\begin{aligned}
& \mathrm{Au}^{0}+\mathrm{CO} \rightarrow \mathrm{Au}^{0} \ldots \mathrm{CO} \\
& \mathrm{Au}^{\mathrm{II}}+\mathrm{OH}_{s}^{-} \rightarrow \mathrm{Au}^{\mathrm{II}} \ldots \mathrm{OH} \\
& \mathrm{Au}^{0} \ldots \mathrm{CO}+\mathrm{Au}^{\mathrm{II}} \ldots \mathrm{OH} \rightarrow \mathrm{Au}^{\mathrm{I}} \ldots \mathrm{COOH}+\mathrm{Au}^{0} \\
& \mathrm{O}_{2}+\square_{s}^{-} \rightarrow \mathrm{O}_{2}^{-} \ldots \square_{s} \\
& \mathrm{Au}^{\mathrm{II}} \ldots \mathrm{COOH}+\mathrm{O}_{2}^{-} \ldots \square_{s} \rightarrow \mathrm{Au}^{\mathrm{II}}+\mathrm{CO}_{2}+\mathrm{HO}_{2}^{-} \ldots \square_{s}(5) \\
& \mathrm{Au}^{\mathrm{II}} \ldots \mathrm{COOH}+\mathrm{HO}_{2}^{-} \ldots \square_{\mathrm{s}} \rightarrow \mathrm{Au}^{\mathrm{II}}+\mathrm{CO}_{2}+ \\
& 2 \mathrm{OH}_{s}^{-}+\square_{s}(6) \\
& \mathrm{Au}^{\mathrm{II}}+\square_{\mathrm{s}} \rightarrow \mathrm{Au}^{\mathrm{II}}+\square_{s}^{-}
\end{aligned}
$$

The nett reaction, ie $2 \mathrm{CO}+\mathrm{O}_{2} \rightarrow 2 \mathrm{CO}_{2}$, is obtained by doubling the processes represented by Equations (1) - (3) and then adding all the processes in the set.

The symposium provided a further opportunity, during the final 'wind-up' session, to discuss and advertise the intention to provide standard reference catalyst(s). Liaison with Professor Geoffrey Bond and Dr Haruta has now produced an outline plan for making, characterizing and distributing this catalyst. Feedback of information between the various groups using the reference catalysts will be beneficial and the
World Gold Council, who will be the distributors, will be in an ideal position to monitor the results and publish news on developments in this new technological field, via publication of the results in CatGold News and Gold Bulletin.

In summary, this was a conference attended principally by academics but there was significant interest shown by industrialists in the promise of applications for gold catalysis, and there is optimism about substantial applications being realized within a 5 - 10 year time period. There is still considerable scope, however, for improving the reproducibility and increasing the selectivity and durability of gold catalysts, which are both highly desirable requirements for applications. Feasibility projects should be encouraged which relate to firmly establishing basic technology for practical applications in the fuel cell, pollution control and/or chemical synthesis areas. WGC is currently defining a strategy based on the above which will lead to the most desirable kind of conference for Catalytic Gold II in 2003, probably to take place in North America, and is itself looking to fund feasibility studies in catalysis by gold (see GROW programme details on the inside back cover of this issue). Certainly both academics and industrialists will be keen to be involved!

\section{ACKNOWLEDGEMENT}

We thank Dr Qiang Xu of the National Institute of Advanced Industrial Science and Technology (AIST), Osaka, Japan and the Organizing Committee of EuropaCatV for permission to publish some of the reaction schemes in Dr Xu's paper.

\section{REFERENCES}

1 D.T. Thompson, Gold Bull., 2001, 34, 56

2 D.T. Thompson, Gold Bull., 1998, 31, 111-118; 1999, 32, 12-19. A. Grohmann, H. Schmidbaur in 'Comprehensive Organometallic Chemistry II', ed. E.W. Abel, F.G.A. Stone, G. Wilkinson and J.L. Wardell, Pergamon Press, 1995, Vol. 3, 1- 56. H. Schmidbaur, Naturw. Rdsch., 1995, 48, 443-451

3. Haruta, Catal. Today, 1997, 36, 153-166

G.C. Bond and D.T. Thompson, Catal.Rev-Sci.Eng., 1999, 41, 319

M. Haruta, T. Kobayashi, H. Sano and N. Yamada, Chem. Lett. (1987) 405.

CatGold News, World Gold Council, London, September 2001

G.C. Bond and D.T. Thompson, Gold Bull., 2000, 33, 41 - 51

\footnotetext{
Continued from page 119

13 G.C. Bond and P.A. Sermon, Gold Bull., 1973, 6, 102

14 P.A. Sermon, G.C. Bond and P.B. Wells, J. Chem. Soc., Faraday Trans. I, 1979, 75, 385

15 G.A. Ozin, Acc. Chem. Res., 1977, 21, 10

16 D. McIntosh and G.A. Ozin, Inorg. Chem., 1976, 15, 2869; 1977, 16, 51
}

\footnotetext{
17 M. Mavrikakis, P. Stolze and J.K. Norskov, Catal. Lett., 2000, 64, 101

18 G.C. Bond and D.T. Thompson, Gold Bull., 2000, 33, 41

19 H. Liu, A.I. Kozlov, A.P. Kozlova, T. Shida and Y. Iwasawa, Phys. Chem. Chem. Phys., $1999,1,2851$
} 